This item was submitted to Loughborough's Research Repository by the author.

Items in Figshare are protected by copyright, with all rights reserved, unless otherwise indicated.

\title{
Service startups and creative communities: Two sides of the same coin?
}

PLEASE CITE THE PUBLISHED VERSION

https://doi.org/10.1080/14606925.2019.1592809

PUBLISHER

Informa UK Limited, trading as Taylor \& Francis Group

VERSION

AM (Accepted Manuscript)

LICENCE

CC BY-NC-ND 4.0

REPOSITORY RECORD

Bofylatos, Spyros, and Ida Telalbasic. 2019. "Service Startups and Creative Communities: Two Sides of the Same Coin?”. figshare. https://hdl.handle.net/2134/37777. 


\title{
Service Startups and Creative Communities, two sides of the same coin?
}

\author{
Corresponding author: \\ Dr. Spyros Bofylatos, \\ Course Instructor \\ University of the Aegean, Department of Product and Systems Design Engineering \\ Hermoupolis, Syros, Greece, GR-84100 \\ Tel: +30 2281097150 \\ bofy@aegean.gr \\ http://www.syros.aegean.gr/users/bofy \\ http://orcid.org/0000-0002-6743-2081 \\ Dr Ida Telalbasic, \\ Lecturer, Institute for Design Innovation, \\ Loughborough University London Institute for Design Innovation \\ 3 Lesney Avenue, Here East, Queen Elizabeth Olympic Park, London E15 2GZ, UK \\ Tel. +44 (0)7727801000 \\ i.telalbasic@lboro.ac.uk \\ http://www.lborolondon.ac.uk/about/staff/ida-telalbasic/ \\ https://orcid.org/0000-0001-8935-5059
}

\section{Author Bios}

Dr. Spyros Bofylatos is a course instructor in the Department of Products and System Design Engineering of the University of the Aegean with a degree in design engineering. His research interests include design for sustainability, social innovation, craft, coDesign, open design, service design, critical thinking and disruptive practices. His work is based on creating meaningful dialogue between the theoretical framework, physical artefacts, products of the design process and the society in which those ideas manifest

Dr Ida Telalbasic is a lecturer at the Institute for Design Innovation, Loughborough University London, contributing to research, teaching and enterprise activities in the area of design innovation management. Her research focuses on service design innovation and strategy, including research projects that deploy a design-driven approach for developing community development projects with a focus on social entrepreneurship, social innovation and incubation activities in local contexts. Her experience includes developing scaling-up methodologies for social innovations and contribution in a startup project aimed to design collaborative services to boost social innovation in smart cities. She is a program director for the Entrepreneurial Design Management programme and a visiting lecturer at Central Saint Martin's College (Innovation Management) and Ravensbourne (Business Design) in London.

\section{Acknowledgements:}

The authors would like to thank Dr Jamie Brasset, Reader in Philosophy, Design \& Innovation, Central Saint Martins, UAL, Andriana Nassou and Alkisti Efthymiou for their valuable comments and feedback. 


\title{
Service Startups and Creative Communities, two sides of the same coin?
}

\begin{abstract}
Service Startups and Creative Communities can be seen as the two sides of the same coin. They are both organizations that adopt service dominant logic to create innovative services. These service models are a double-edged sword, they can facilitate the transition towards sustainability or they can support the unjust, neoliberal 'gig economy' that commodifies work and further elongates social inequalities.
\end{abstract}

Even though, these organizations are different on some levels and by understanding their similarities and differences a wider issue emerges, the conflict of values between eco-modernist and radical approaches to sustainability. By understanding the two antithetical positions of this spectrum, design can create the conditions that will allow designers to have a more informed choice when designing. Finally given how these differences point to a wider issue, provides a philosophical springboard for further debates in the field of design.

KEYWORDS: service design, service startups, creative communities, social innovation, design for sustainability

\section{Introduction}

This paper aims to present both similarities and differences between two types of emerging approaches towards sustainability. This speculative philosophical account aims to frame two emerging paradigms that utilize overlapping methods but employ different goals, structure, and values. The first approach relates to service startups as platforms that enable a multiplicity of possible interactions. The other approach relates to creative communities that create new solutions by reshaping existing resources. By highlighting more broadly the main distinctions between these two approaches, looking through the lenses design for sustainability, transition design or sustainment, the underlying conflict of values becomes apparent. This article will frame the debate that will provide valuable insights that will ultimately inform the designer's choice in designing for sustainability. In the first part of the paper, the shift towards the service dominant logic is discussed and the two dialectically opposing organisations, service startups and creative communities, are presented. In the second section of the paper, the two antithetical positions associated with design and sustainability are discussed 
again, the focus being on how the different values create these differences at the core of these organisations. The key discourse is based upon the notion of how the emerging systems of value are influencing the design process and its relation to sustainability. The main position is that the differences between the two organisations mirror the differences between eco-modernity and transitional systems of values.

In recent years humanity has started to poke and prod at the limits of the planet's carrying capacity. This brought forth a movement that is based on the understanding that infinite growth is impossible on a finite planet and running into the limits of the planet will cause the collapse of the ecosystem, the economic system, and human society as a whole. Sustainability is broadly associated with creating a system that will avoid this collapse and will perpetually safeguard humanity's future (Brundtland, 1987). Design for sustainability and the study of sustainability in general has emerged as an important field in recent years. Contemporary society is unsustainable by design, yet designerly tools have the capacity to alleviate the problem by being applied with a different mindset. The environmental impacts of a project are pretty much decided during the design process (Design Council, 2002) and as such design has the capacity to create alternatives. In this design discourse, this shift has been approached from all sides. The spectrum of the discourse associated with sustainability is framed by the idea of eco-modernity on one side and that of the transition towards sustainment on the other side.

\section{Service thinking, from ownership towards access}

Looking at some formal definitions of design, different key points emerge that substantially define the core of the design agenda. Meroni \& Sangiorgi (2011) highlight the distinction in designing for services, instead of design of services or service design. This key preposition captures the transformative process where design between people is not the final result, but rather the 'action platform' that enables a multiplicity of possible interactions (Manzini in Meroni and Sangiorgi, 2011). Meroni and Sangiorgi (2011) define a service as a regulated form of co-production of benefits between two or more parties, aiming at solving a certain problem/need through the application of knowledge and skills. The authors explain how services are special artifacts that are co-created and co-experienced with, by and among users and where the service interaction is consequently a form of social interaction. Services have existed and been organised in various forms. Consciously designed services that incorporate new business models are empathetic to user needs and attempt to create new socioeconomic value in society. Service design is considered to be essential in today's knowledge-driven economy (Copenhagen Institute for Interaction Design in Stickdorn and Schneider, 2010). The outcome of designing for services results in an enabling stage where certain actions are encouraged through the design for service users. Furthermore, a more people-centred and dynamic approach to new service development is part of a bridging process between service design and design thinking for service innovation (Sangiorgi and Prendeville, 2017). 
The shift from products to services, in terms of moving away from 'ownership towards access' (Rifkin, 2000) is inherent to the notion of 'dematerialization'. This has significantly dictated the way new emerging service systems are perceived and sensed, offering entirely new experiences in mobility, housing, travel etc. The main shift is that of perspective, products are systems that embody 'value in exchange' whereas service are systems that produce 'value in use' (Edvardsson et al. 2005; Grönroos 2008). These perspectives shift the focus more on the process of value creation due to the shift from considering value as embedded into tangible goods toward conceiving value as co-created amongst various economic and social actors (Vargo and Lusch, 2008). If this shift is investigated in more details, it becomes apparent that there is a move towards re-conceptualizing products: where products are becoming the means for the successful function of services, eg. a bicycle specifically designed to enable operation of a bike-sharing service (Meroni and Sangiorgi, 2011). This 'functional thinking approach' claims that to reduce material throughput in the economy, it is important to provide the 'functions' themselves i.e. mobility as opposed to bicycles, cars etc. (Manzini et al., 2001). The service discourse proposes two conceptual directions as paradigms for services: the first 'interaction paradigm' considers the interactive nature of services, focusing on the actual experience. Pacenti (1998) defines service design as an area where interactions between the service and the user take place. The second 'functional paradigm' refers to product-service-system design as alternative models for long-term sustainability. It considers not the means to an end, but conceptually exploring wider possibilities to achieve the same aim with less or no objects as strategies for sustainable consumption and production (Meroni and Sangiorgi, 2011).

The shift towards a service dominant model points to a shift in values and cultural patterns. The adoption of value in exchange through service design challenges traditional materialistic patterns as the product becomes a touchpoint for a service instead of a fetishised status symbol. According to Sorokin (1937) the circles of human history present three strikingly consistent phenomena. There are two opposed elementary cultural patterns, the materialistic (Sensate) and spiritual (Ideational). Every society tends to alternate between materialistic and spiritual periods, sometimes with transitional, mixed periods. Times of transition from one orientation to another are characterized by a markedly increased socio-economic transformation. The sensate characteristics of the modernist doctrine are the root causes behind materialism and consumerism, shaping the idea of design. The approach adopted within service thinking is one that is conducive to a transition from materialistic systems of values to ideational cultural patterns. Understanding how service design can exist within two distinct and antithetical systems of values can provide insights that are valuable in both the field of design for sustainability as well as service thinking. If we were to look at transition as a timeline (Irwin et al., 2015) we need tools and solutions that function on the micro, meso and macro level. Therefore, small incremental changes, need to be coupled with utopian, speculative visions of the future. By contrasting the difference between the two organisations working with different time frames, a pathway emerges that can lead to the future starting today. 


\section{Creative communities, carriers of new values}

The first antithetical position associated with design and sustainability are the creative communities. This bottom-up informal organisation adopts social innovation to codesign solutions to problems of their everyday life and these solutions take the form of collaborative services. The term social innovation refers to new ideas (products, services and models) that simultaneously meet social need and create new social relationships or collaboration. They are the innovations that are both good for society and enhance society's capacity to act. (Murray et al., 2010). Communities that collectively create, foster and manage new solutions to problems of their everyday lives by reshaping already existing solutions, are called creative communities (Meroni, 2007). These communities of people use the diffuse design capacity to solve the problems in their environment through the design of collaborative services (Manzini, 2015). They are sharing their visions and looking at problems from different perspectives, creating social innovation that are likely to evolve into structured organizations or business ventures. There are many good examples where it is possible to identify that services are affecting habits, behaviours and therefore lifestyles, enabling the transformation of organisations (Sangiorgi, 2011). As a result, services are dematerializing people's lives and creating new value systems and social networks of reciprocal benefits. Some of them illustrate communal benefits, such as cohousing, co-working, co-using, co-learning (Manzini and Jegou, 2008) where idle capacities are transforming into valuable assets that through design can become accessible to a vast majority of communities.

The solutions put forward by these creative communities reduce the flows of materials and energy (Manzini et al., 2001) to create a new economic model. The model adopted at smaller scale is characterised by participation, transparency, trust and honesty (Cook, 2004). As such these grassroots initiatives can be seen working towards degrowth (D'Alisa et al., 2014). These transitions are all linked with the transition towards sustainability, a deep reshaping of human society not an ecologically sound incantation of modernity or a techno-utopia. In the context of this paper, creative communities are relevant due to the adoption of service design methods in order to embody an alternative system of values and provide new solutions to everyday problems caused by the collapse of traditional support structures.

The implementation of collaborative services points to the importance of the service design approach in the context of designing for social innovation. Collaborative services can defined in two ways: those that actively involve final users to assume the role of service co-designers and co-producers (Manzini, 2015) or services which are designed and utilised on a local scale, to meet specific needs in a community and create more sharing, and exchange of resources through innovation and participation (Daniel et al., 2010). These services are the main offering of creative communities engaged in social innovation. The adoption of the service dominant logic is important as it aligns with the general goals of social innovation. The design and use of such systems is not exclusive to creative communities. Between the two edges of the spectrum a wealth of different approaches with different parameters and structures exist. 
Social enterprise is an example of organisations that are aligned with the goals associated with the emergence of a sustainable society. This points to a taxonomy of approaches to sustainability that takes the form of a spectrum more than that of a thesis-antithesis. These types of service systems have a greater capacity to lead down pathways that are conducive to sustainable lifestyles. However, apart from an implicit disposition to go down such avenues, they can easily have all of their transformative and emancipatory characteristics stripped away. This points to an 'adversarial' (Disalvo, 2012) relationship between the existing system of values of the 'Hegemonic ideology' (Zizek, 2014) this is evident in the proposed taxonomy of dimensions of organisations producing service models. Modern lifestyles are unsustainable and a deep reshaping of our society is necessary to move forward.

\section{Service Startups, more of the same?}

The second antithetical position associated with design and sustainability is the design of service startups. The outcome of designing for services results in an enabling stage where certain actions are encouraged through the design for service users (Meroni and Sangiorgi, 2011). In order to foster interactions to occur in the co-creation of value, the role of the designer is to facilitate and act as an enabler with these collaborative platforms (ibid.). Service design is the application of established design process and skills to the development of services. The role of the designer also extends in two creative and practical ways: either to improve existing services and innovate new ones (Stickdorn and Schneider, 2010). The term service startup refers to a type of lean startup (Ries, 2011) that instead of being focused on the product is focused on producing a service model. Such startups utilise the idea of the sharing economy, new technologies and includes the idea of platforms to innovate new solutions to everyday problems.

The main method of these organisations is the Minimum Value Service (MVS) (Pinheiro, 2014) as opposed to the traditional Minimum Valuable Product (MVP) approach of lean startups. This shift has been long time coming in the entanglement between design and enterprise and the shift from an aesthetic and functional focus of the design discipline towards strategy and enterprise (Van Erp, 2011). These types of commercial organisation exist within the 'sharing economy' (Hamari et al., 2016). The sharing economy may take a variety of forms, including using information technology to provide individuals with information that enables the optimization of resources through the mutualisation of excess capacity in goods and services (Cohen et al., 2014). The frame for this emerging phenomenon is ranging between a potential pathway to sustainability, to a dystopian form of neoliberalism (Martin, 2016). Companies like Uber and Taskrabbit instrumentalise labour, turning workers into freelancers who have to move from 'gig to gig' or perish. This process coupled with the collapse of traditional support structures weakens the social fabric and increases the divide between the rich and the poor.

It does not have to be like this. In this crossroad between utopia and dystopia, designers act as the mediators of materiality in the physical world and sociality of human communities (Dilnot, 1982) have to be conscious of their burden and act (or 
refuse to act) accordingly. The role of the designer in this context is to engage in an iterative design process aiming to identify the minimum desirable service. Additionally, the role is to evaluate if the core offering of the organisation is desirable and competitive in the market or a pivot in the business model is needed.

\section{Service Startups + Creative Communities = 'frenemies'?}

What becomes evident in first sight is that both creative communities and service startups are organisations that use service design methods to create value in use. However, the differences between the two can be used to frame the central debate on sustainability. The debate on whether a 'socio-technical fix' is possible within the current system of values (modernity) or a transition to the next era of human development 'sustainment' is necessary for sustainability. Using service design concepts enables a comparison on how the differences in values shape the dimensions of these organisations with respect to eco-modernity and the transition towards 'sustainment'. The differences between service startups and creative communities can be viewed from Table. 1, where the parameters have emerged from an extensive overview from literature and through the authors professional capacity. This general overview includes certain parameters such as: essential goals, participation initiator, trust reinforcement, operational structures, decision making format, power implementation, spatial diffusion, motivation for participation, external approach, value creation, knowledge diffusion, and interaction typology. The choice of parameters is based on how the design approach is informed and influenced by these characteristics, by this richer understanding the selection of more appropriate tools and methods is achieved depending on the characteristics of the organisation.

\begin{tabular}{|l|l|l|l|}
\hline PARAMETERS & SERVICE STARTUP & $\begin{array}{l}\text { CREATIVE } \\
\text { COMMUNITY }\end{array}$ & \\
\hline ESSENTIAL GOALS & PROFIT & FLOURISHMENT & $\begin{array}{l}\text { (Cipolla \& Manzini } \\
2009)\end{array}$ \\
\hline $\begin{array}{l}\text { PARTICIPATION } \\
\text { INITIATOR }\end{array}$ & GUIDED & ACTIVE & $\begin{array}{l}\text { (Junginger, Sangiorgi } \\
2009)\end{array}$ \\
\hline $\begin{array}{l}\text { TRUST } \\
\text { REINFORCEMENT }\end{array}$ & REPUTATION & PROCESS & (Sangiorgi 2011) \\
\hline $\begin{array}{l}\text { OPERATIONAL } \\
\text { STRUCTURE }\end{array}$ & HIERARCHICAL & FLAT & $\begin{array}{l}\text { (Jegou \& Manzini } \\
\text { 2008) }\end{array}$ \\
\hline $\begin{array}{l}\text { DECISION MAKING } \\
\text { FORMAT }\end{array}$ & OLIGARCHIC & DEMOCRATIC & (Sangiorgi 2011) \\
\hline $\begin{array}{l}\text { POWER } \\
\text { IMPLEMENTATION }\end{array}$ & CENTRAL & DISTRIBUTED & $\begin{array}{l}\text { (Junginger, Sangiorgi } \\
\text { 2009) }\end{array}$ \\
\hline SPATIAL DIFFUSION & GLOBAL & LOCAL & (Manzini 2015) \\
\hline $\begin{array}{l}\text { MOTIVATION FOR } \\
\text { PARTICIPATION }\end{array}$ & EMPLOYMENT & $\begin{array}{l}\text { SELF- } \\
\text { DETERMINATION }\end{array}$ & (Kossoff 2015) \\
\hline $\begin{array}{l}\text { EXTERNAL } \\
\text { APPROACH }\end{array}$ & COMPETITIVE & COLLABORATIVE & $\begin{array}{l}\text { (Cipolla \& Manzini } \\
\text { 2009) }\end{array}$ \\
\hline VALUE CREATION & CLOSED & SHARED & Meroni 2007) \\
\hline $\begin{array}{l}\text { KNOWLEDGE } \\
\text { DIFFUSION }\end{array}$ & PROPRIETARY & OPEN & (Murray et al.2010) \\
\hline
\end{tabular}




\begin{tabular}{|l|l|l|l|}
\hline $\begin{array}{l}\text { INTERACTION } \\
\text { TYPOLOGY }\end{array}$ & B2B / C2B & P2P & (Murray et al.2010) \\
\hline
\end{tabular}

Table 1 Service Startups and Creative Communities according to qualitative parameters defined through service design concepts.

The essential goals generally reflect the mission and value propositions of service startups whose aim is to make profit, while creative communities strive for economic, social and environmental betterment. This betterment reflects a truly collaborative approach where the notion of contributing to a community, in turn benefits the $\mathrm{N}$ number of people that are part of that community, network, cluster, etc. The participation initiator relates to the essential goals parameter, since participation, in the case of service startups requires a guided approach, demonstrating both how the decision-making process and power implementation are imposed from a top-down source. On the other side, creative communities consider participation and peer interactions as the main form of democratic value creation that is self-initiated, codesigned and co-managed, making sense locally. This is in turn connected to the reinforcement of trust where service startups serve as a main mechanism for building reputation. With creative communities, trust is not a mechanism, but a process that enables the building of a collaborative society based on talent sharing and knowledge economy by accelerating the exchange of social capital between different people.

To further elaborate on the indicated parameters, the operational structure refers to both centralised and decentralized systems, where the centralised type refers to ownership, management and responsibility that can be monitored and governed by a central source, while the latter type is distributed among community members. With respect to the differences in operational structure, it is possible to identify the characteristics for both the decision-making format and power implementation that are closely connected. The service startups deploy an oligarchic process where the power is established centrally and rests within the hands of a few (Gunasekaran et al. 2011), while the creative communities deploy democratic decision-making processes since the power is equally distributed (Meroni, 2017).

The spatial diffusion is linked to the initiation determinants, where by looking at who the initiation determinants are, it can give evidence of how the system is perceived and organised. This mainly refers to the systems either being open, where the possibility for replication and scaling can be achieved in other locations. While on the other hand, if the system is closed, it targets a bounded and specific geographic area. The parameter of motivation for participation, underlines the differences more extremely. This is because service startups strive to be alternative business models that offer additional employment. This is both positive, in a general sense, but also interest-based. However, the motivations for users to become active members is not entirely driven by social innovation goals but is considered as an additional enabler for different types of economic interactions to occur, thus creating monetary benefits on small or large scales. On the contrary, creative communities emerge because the initial motivations lie in the self-governing and co-creation of meaningful practices that are based on community-driven principles and driven by self-determination. 
The external approach highlights an important aspect in the analysis of service startups that fosters competition, where value creation is closed and knowledge diffusion is proprietary. On the contrary, creative communities foster collaboration and value creation is shared and knowledge diffusion is open eg. creative commons. The first view shows how even new service startups are based on hard capitalist ideas and individualism that are merely rearranged in a previous setting and led by self-interest mainstream. On the other hand, creative communities accelerate collaborative services to create a new culture of exchanging and working together. Consequently, there is an opportunity for this new culture to grow because people are given the tools to realize their visions through a community and move away from the 'business-as-usual' approach towards a new paradigm of operating. Finally, the interaction patterns give evidence of types of business-to-business (B2B) and customer-to-business (C2B) transactions as the main forms of interactions for service startups. Creative communities enable peer-to-peer (P2P) interactions and this highlights the insights from previous external approach that are here further reinforced through the interaction patterns.

This comparative analysis sheds light to a matrix of opposing values that can be identified between creative communities and service startups. The distinction in parameters between these two sides of the same coin can help create a holistic understanding of the differences between emerging and dominant values. Both creative communities and service startups can be steered towards design for sustainability with the first working on the meso and macro level (in the next 30-100 years) of the timescale and the latter on the micro level (the today and tomorrow). The wealth of different practices that can be witnessed, with its successes and failures, can provide the blueprint to tread with care, responsibility and virtue. However, the same tools that can act as enablers of sustainable lifestyles can trap us in a labyrinth of our own design.

\section{Design for sustainability, chasing an 'ignis fatuus'}

The inability of modernity to work within the planet's carrying capacity has created a society that is unsustainable, and unless some of the core values change, it cannot be salvaged. The rise of scientific operationalism (Cottingham, 2005) has cast other ways of knowing by the wayside. The fragmented perspective of modernity allows for approaches that address the symptoms but not the 'disease' to dominate the mainstream as viable solutions. The ethics stemming out of this 'rationalistic' way of being in the world instrumentalize both the environment and social interactions. This fosters the conditions that have led to a scale of environmental degradation that puts our existence on the planet in jeopardy. As we transition towards an ideational cultural pattern we will have to address the loss of meaning and a work towards the reconstitution of narrative unity (Walker, 2017). Sustainability is a wicked problem (Ehrenfeld 2008) and as such it is made up of interconnected and impossible to deconstruct problems. Approaches that aim to reduce environmental or societal impacts whilst preserving the current model of growth are impossible to lead to sustainability. These approaches reduce unsustainability but one must ask oneself 
whether reducing unsustainability to zero lead to the emergence of sustainability? (Ehrenfeld, 2008).

The answer to the question regarding the nature of sustainability leads to a crystal clear distinction between approaches to sustainability. The two antithetical positions presented here can be seen as a spectrum within which all ideas concerning sustainability can be situated as seen in figure 1 . This process aims to provide service designers with a holistic view by incorporating, taxonomizing and providing a solid foundation upon which different approaches can be analysed. The goal is not to choose which way to design for sustainability is better or be pedantic but to provide a platform that will enable a more robust debate and empower designers to have a better-informed choice. In addition, aspects of eco-modernist approaches provide a pragmatic short-term way to apply incremental changes. On the other side, more radical, long-term approaches contain a glimpse of utopias necessary to act as a lighthouse guiding us into the future.

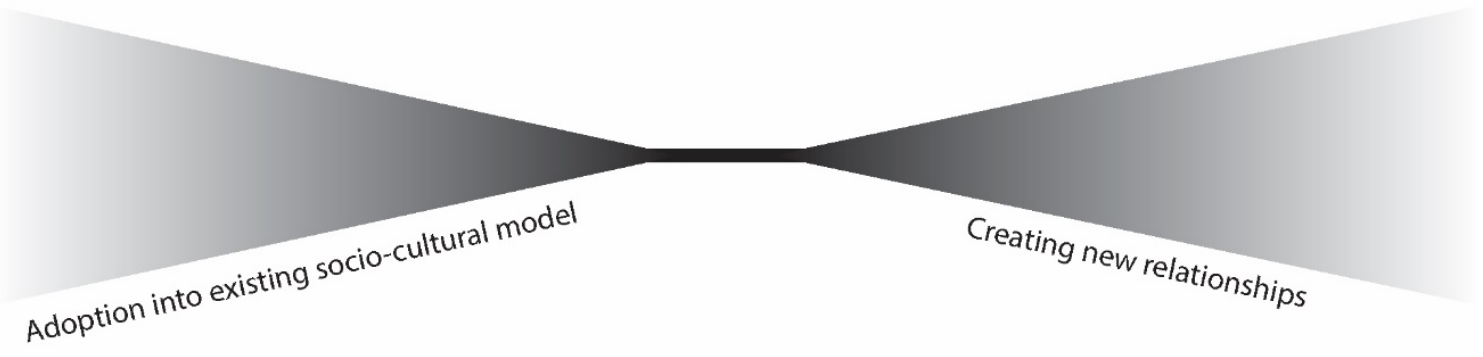

Figure 1 The eco-modernity sustainment. Designed by Taxiarxis Balaskas

\section{Eco-modernist approaches, looking at the 'symptoms'}

Sustainable design has time and time again been criticized as being too marketoriented and offering to solution to the problems that lead to unsustainable behaviour and consumption. Approaches such as factor four (Weizsäcker et al., 1995), factor ten (Bleischwitz et al., (Eds), 2009) or natural capitalism (Hawken et al., 1999) aim to create more rational products, services and business models with respect to the environment and social well-being. However, increasing resource efficiency does not necessarily reduce consumption. The rebound effect (Herring and Sorrell, 2009) has proven that sustainability is a long-shot in the existing socio-economic system of consumption. In general, eco-modernist approaches seek to reform the current model and identify that the designer's role is to mediate the process of production with consumption.

This process lacks a critical element towards the reasons behind unsustainability and can lead to 'greenwashed' products. It addresses the symptoms while turning a blind eye to the root cause of the problem. In general, all versions of eco-efficiency share four key characteristics:

(1) Confidence in technological innovation as the main solution to unsustainability; 
(2) Reliance on markets as the principal actor of transformation;

(3) Trust in the markets ability to function in a way that will aid the emergence of sustainability;

(4) 'Growth philia: there is nothing wrong with growth as such. Moreover, with 'cradle-to-cradle, growth is conducive to sustainability per se

(Boulanger, 2010).

These eco modern approaches can reduce the unsustainability but are reformist and in accordance with the contemporary system of values that has led humanity down this path.

\section{Sustainment, curing the 'disease'}

On the other side of the sustainability-unsustainability dialectical spectrum, it is the transformative and radical ideas that emerge from the idea that reducing unsustainability to zero does not solve the root causes of unsustainability (Ehrenfeld, 2013). Yet, it is a new society that has to be grounded on a new system of values and compatible with sustainability. Sustainable development addresses and attempts to reduce unsustainability. However, reducing unsustainability, although critical, does not and will not create sustainability (Ehrenfeld, 2008). Sustainability has been characterized as a 'profound political and economic change' (Wood, 2008), 'a significant structural change' (Thackara, 2005, p.18), 'a change in behaviour' (Bharma et al., 2011), 'radical social and technical change' (Ryan, 2008) and the possibility that human and other life will flourish on the planet forever (Ehrenfeld, 2008), to name but a few. What becomes evident is a converging array of ideas that point towards a shift from modernity. Tony Fry (2004) refers to the shift from modernity as 'sustainment', a state in which all human institutions and structures act to secure possibility of long term futures rather than damaging the conditions that enable the existence of life on the planner. The transition towards sustainment may be equated in scale with the epochal shift of the 18th century Enlightenment movement which founded many of the concepts, value systems and institutions that persist into the 21 st century.

Transition Design is a design methodology that acknowledges that we are living in 'transitional times'. Again, the central premise is tied to the need for societal transitions from the modernist project towards more sustainable futures (Irwin et al., 2015). Transition Design advocates the re-conception of entire lifestyles and the 'reconstitution of everyday life' (Kossoff,2015), with the aim of making them more place-based, convivial, participatory and harmonizing them with the natural environment. Design for Service and Design for Social Innovation are, according to transition design, its precursors. The need for this third approach is based upon the necessity for a longer-term vision. Through this extended timescale, the solutions developed are rooted in new, more sustainable socio-economic and political paradigms (Irwin, 2015). Transition visions provide greater leverage for projects undertaken in the service and social innovation sectors by networking and linking them together to form more effective transitional steps toward a desired future. Transition design is deployed around a heuristic model to characterize four different but interrelated and mutually influencing areas: Vision for Transition, Theories of Change, Posture and Mindset, New ways of Designing (Irwin et al., 2015). These four pillars point to a future facing and conductive to a change approach. What comes forward from a critical mass of 
bibliography from the sustainability discourse is that many of the assumptions on which the system we live is based are injudicious. Only by facing them directly in a critical way, will it be possible to alleviate the problems they have caused and move towards new, sustainable ways of being in the world. The design of services as an emerging way of designing has to take these emerging ideas into account and integrate them in order to produce solutions that will foster this transition. Striking a balance between the new and the old, working for the future, today has to be the way to make utopia a reality.

\section{Conclusions}

In this paper it has been postulated that the significant differences in almost all dimensions between service startups and creative communities points to something different. This divide exists because the two organisations embody different systems of values. These values guide the design decisions and the way they are governed on an organisational scale. This phenomenon is deeply tied with the posture needed to transition towards sustainment in relation to the need for a technical fix put forward by eco-modernity. This correlation, in our view, further supports the value of the spectrum of sustainability approaches proposed both in theory and in practice. The approach presented in this paper is not about red lines, it is not about getting entrenched in a ideologically informed position and holding it against all odds. It is about finding common ground. Striking a balance between what is possible today and what has to be done in the future for it to exist is this common ground. In this era where our previous assumptions have led us down a path that is characterized by divisiveness, empathising and understanding the 'other' side is necessary. The limitations of this speculative study are complementary to the aforementioned positive aspects.

Translating these guidelines into realistic actionable steps still remains a challenge that several future studies need to address. Creating and analyzing empirical data, undertaken by future studies of the two different types of organizations will be the next steps of this research direction.

At the same time we find ourselves living in a transitional period where the promises of growth and prosperity are challenged every day and this process causes the reevaluation and change of our core values. The service system perspective plays a significant role in determining the directions of the systems of values embodied within aforementioned systems. Re-conceptualizing products, as a means for values to be experienced, and not embodied, fosters the shift from the materialistic towards the ideational. Identifying and selecting the future scenarios that are desirable and sustainable is a challenge and opportunity for service design moving forward. Today, more than ever, people and organisations challenge the status quo and at the same time the 'hegemonic ideology' neutralises, adapts and absorbs any opposing ideas (Zizek, 2011). In this clash of values and the previously described neutralisation of radical ideas, the narratives become warped and the ability to have an informed choice is complicated. These organisations have the capacity to act as catalyst for change and be part of a deep restructuring of human societies. This could potentially 
be achieved by fostering an alternative system of values. At the same time, they can act as the most ruthless incantation of neoliberal capitalism, putting monetary growth above everything, promoting environmental degradation and social exploitation. The choice of which future we want is not up to the tools but on those who wield them. Choosing by flipping the proverbial coin is not a sound way, we have to take a hard, critical look at each side and select the one that is compatible with our personal and societal goals.

\section{References}

-Boulanger, Paul-Marie. "Three strategies for sustainable consumption." SAPI EN. S. Surveys and Perspectives Integrating Environment and Society 3.2 (2010).

- Cohen, Boyd, and Jan Kietzmann. "Ride on! Mobility business models for the sharing economy." Organization \& Environment 27, no. 3 (2014): 279-296.

-Cook, David. The Natural Step: towards a sustainable society. No. 11. Green Books, (2004).

- Cottingham, John. The spiritual dimension: Religion, philosophy and human value.

Cambridge University Press, (2005).

- D'Alisa, Giacomo, Federico Demaria, and Giorgos Kallis, eds. Degrowth: a vocabulary for a new era. Routledge, 2014.

- Daniel, Ronny, Sophia Horwitz, Laura MacPherson, and Maurita Prato. "Collaborative services: Communities innovating towards sustainability." (2010).

- Dilnot, Clive. "Design as a socially significant activity: an introduction." Design Studies 3, no. 3 (1982): 139-146.

- Herring, Horace, and Steve Sorrell. "Energy efficiency and sustainable consumption." The Rebound Effect, Hampshire (2009).

-Irwin, Terry. "Transition design: A proposal for a new area of design practice, study, and research." Design and Culture 7, no. 2 (2015): 229-246.

- London: Design Council . Design Council, Annual Review 2002 (2002)

-Manzini, Ezio. Design, when everybody designs: An introduction to design for social innovation. MIT press, (2015).

- Martin, Chris J. "The sharing economy: A pathway to sustainability or a nightmarish form of neoliberal capitalism?." Ecological economics 121 (2016): 149-159.

- Thackara, John. In the bubble: designing in a complex world. MIT press, 2006.

- Vargo, Stephen L., and Robert F. Lusch. "Service-dominant logic: continuing the evolution." Journal of the Academy of marketing Science 36, no. 1 (2008): 1-10. - Von Weizsäcker, Ernst Ulrich, Ernst Ulrich Weizsäcker, Amory B. Lovins, and L. Hunter Lovins. Factor four: doubling wealth-halving resource use: the new report to the Club of Rome. Earthscan, (1998).

-Wood, Charles H. "Time, cycles and tempos in social-ecological research and environmental policy." Time \& Society 17, no. 2-3 (2008): 261-282.

-Bhamra, Tracy, Debra Lilley, and Tang Tang. "Design for sustainable behaviour: Using products to change consumer behaviour." The Design Journal 14, no. 4 (2011): 427445.

-Bleischwitz, Raimund, Paul Welfens, and ZhongXiang Zhang, eds. Sustainable growth and resource productivity: economic and global policy issues. Routledge, (2017). -Brundtland, Gru, Mansour Khalid, Susanna Agnelli, Sali Al-Athel, Bernard Chidzero, 
Lamina Fadika, Volker Hauff et al. "Our common future." (1987).

-Cipolla, Carla, and Ezio Manzini. "Relational services." Knowledge, Technology \&

Policy 22, no. 1 (2009): 45-50.

-DiSalvo, Carl. Adversarial design. The MIT Press, (2012).

-Edvardsson, Bo, Anders Gustafsson, and Inger Roos. "Service portraits in service research: a critical review." International journal of service industry management 16 , no. 1 (2005): 107-121..

-Edwards, Andres R. The sustainability revolution: Portrait of a paradigm shift. New Society Publishers, (2005).

-Ehrenfeld, John. Sustainability by design: A subversive strategy for transforming our consumer culture. Yale University Press, (2009).

-Ehrenfeld, John R., and Andrew J. Hoffman. Flourishing: A frank conversation about sustainability. Stanford University Press, (2013).

-Fry, Tony. "The Sustainment and its dialectic." Design Philosophy Papers: Collection One (2004): 33-45.

-Grönroos, Christian. "Service logic revisited: who creates value? And who cocreates?." European business review 20, no. 4 (2008): 298-314.

-Hamari, Juho, Mimmi Sjöklint, and Antti Ukkonen. "The sharing economy: Why people participate in collaborative consumption." Journal of the association for information science and technology 67, no. 9 (2016): 2047-2059.

-Hunter Lovins, L., Amory Lovins, and Paul Hawken. "Natural capitalism: creating the next industrial revolution." (1999).

-Irwin, Terry, Gideon Kossoff, and Cameron Tonkinwise. "Transition design provocation." Design Philosophy Papers 13, no. 1 (2015): 3-11.

-Jégou, François, and Ezio Manzini. Collaborative services. Social innovation and design for sustainability. Vol. 1. Polidesign, (2008).

-JJunginger, Sabine, and Daniela Sangiorgi. "Service design and organisational change. Bridging the gap between rigour and relevance." In International Association of Societies of Design Research, pp. 4339-4348. KOR, (2009).

-Gunasekaran, Angappa, Bharatendra K. Rai, and Michael Griffin. "Resilience and competitiveness of small and medium size enterprises: an empirical research." International journal of production research 49, no. 18 (2011): 5489-5509..

-Kossoff, Gideon. "Holism and the reconstitution of everyday life: a framework for transition to a sustainable society." Design Philosophy Papers 13, no. 1 (2015): 25-38. -Manzini, Ezio, Carlo Vezzoli, and Garrette Clark. "Product-service systems: using an existing concept as a new approach to sustainability." Journal of Design Research 1, no. 2 (2001): 27-40.

-Meroni, Anna. Creative Communities. People inventing sustainable ways of living.

Edizioni Polidesign, (2007).

-Meroni, Anna, and Daniela Sangiorgi. "Design for Services (Design for Social Responsibility)." (2011).

-Murray, Robin, Julie Caulier-Grice, and Geoff Mulgan. The open book of social innovation. London: National endowment for science, technology and the art, (2010). -Pacenti, E. "Il progetto dell'interazione nei servizi. Un contributo al tema della progettazione dei servizi." Unpublished PhD Thesis. Milano: Politecnico di Milano (1998).

-Pinheiro, Tenny. "The service startup" (2014)

-Ries, Eric. The lean startup: How today's entrepreneurs use continuous innovation to 
create radically successful businesses. Crown Books, (2011).

-Rifkin, Jeremy. The age of access: The new culture of hypercapitalism. Penguin, (2001).

-Ryan Chris. "Eco-Innovation, A pilot project for the ecodesign of services in eight local councils" in Perspectives on Radical Changes to Sustainable Consumption and Production (2008)

-Sangiorgi, Daniela. "Transformative services and transformation design." International Journal of Design 5, no. 2 (2011): 29-40.

-Sangiorgi, Daniela, and Alison Prendiville, eds. Designing for Service: key issues and new directions. Bloomsbury Publishing, (2017).

-Speier, Hans. "Social and Cultural Dynamics: Vol. III, Fluctuation of Social

Relationships, War and Revolution." (1937): 924-929.

-Stickdorn, Marc, Jakob Schneider, Kate Andrews, and Adam Lawrence. This is service design thinking: Basics, tools, cases. Vol. 1. Hoboken, NJ: Wiley, (2011). -Van Erp, Jan "Designing the total experience, a model for the changing role of the designer" in IASDR 2011 the 4th World Conference on Design Research, (2011) -Walker, Stuart. "Design for life." (2017)

-Zizek, Slavoj. The year of dreaming dangerously. Verso Books, (2012).

-Žižek, Slavoj. Absolute recoil: Towards a new foundation of dialectical materialism.

Verso Trade, (2014). 